\title{
Erratum to: Glowing in the dark: discriminating patterns of bioluminescence from different taxa during the Arctic polar night
}

\author{
Geir Johnsen • Mauro Candeloro • Jørgen Berge • \\ Mark Moline
}

Published online: 18 December 2014

(c) Springer-Verlag Berlin Heidelberg 2014

Erratum to: Polar Biol (2014) 37:707-713

DOI 10.1007/s00300-014-1471-4

The article 'Glowing in the dark: discriminating patterns of bioluminescence from different taxa during the Arctic polar night' belongs to the Polar Night special issue but was mistakenly published in another issue of the journal, volume 37 , issue 5 .

The online version of the original article can be found under doi: 10.1007/s00300-014-1471-4.

G. Johnsen $(\bowtie)$

Applied Underwater Robotics Laboratory, Department of Biology, Norwegian University of Technology and Science (NTNU), Trondheim, Norway

e-mail: geir.johnsen@ntnu.no

G. Johnsen · J. Berge

Department of Arctic Biology, University Centre on Svalbard (UNIS), Longyearbyen, Norway

M. Candeloro

Applied Underwater Robotics Laboratory, Department of Marine Technology, Norwegian University of Technology and Science (NTNU), Trondheim, Norway

J. Berge

Faculty of Biosciences, Fisheries and Economy, Institute of Arctic and Marine Biology, University of Troms $\emptyset$, Troms $\emptyset$, Norway

\section{Moline}

School of Marine Science and Policy, University of Delaware, Newark, DE, USA 